\title{
Emotional Responses to Pleasant and Unpleasant Oral Flavour Stimuli
}

\section{Patrizia Muroni, Roberto Crnjar \& Iole Tomassini Barbarossa}

Chemosensory Perception

ISSN 1936-5802

Volume 4

Number 3

Chem. Percept. (2011) 4:65-71

DOI 10.1007/s12078-011-9093-5

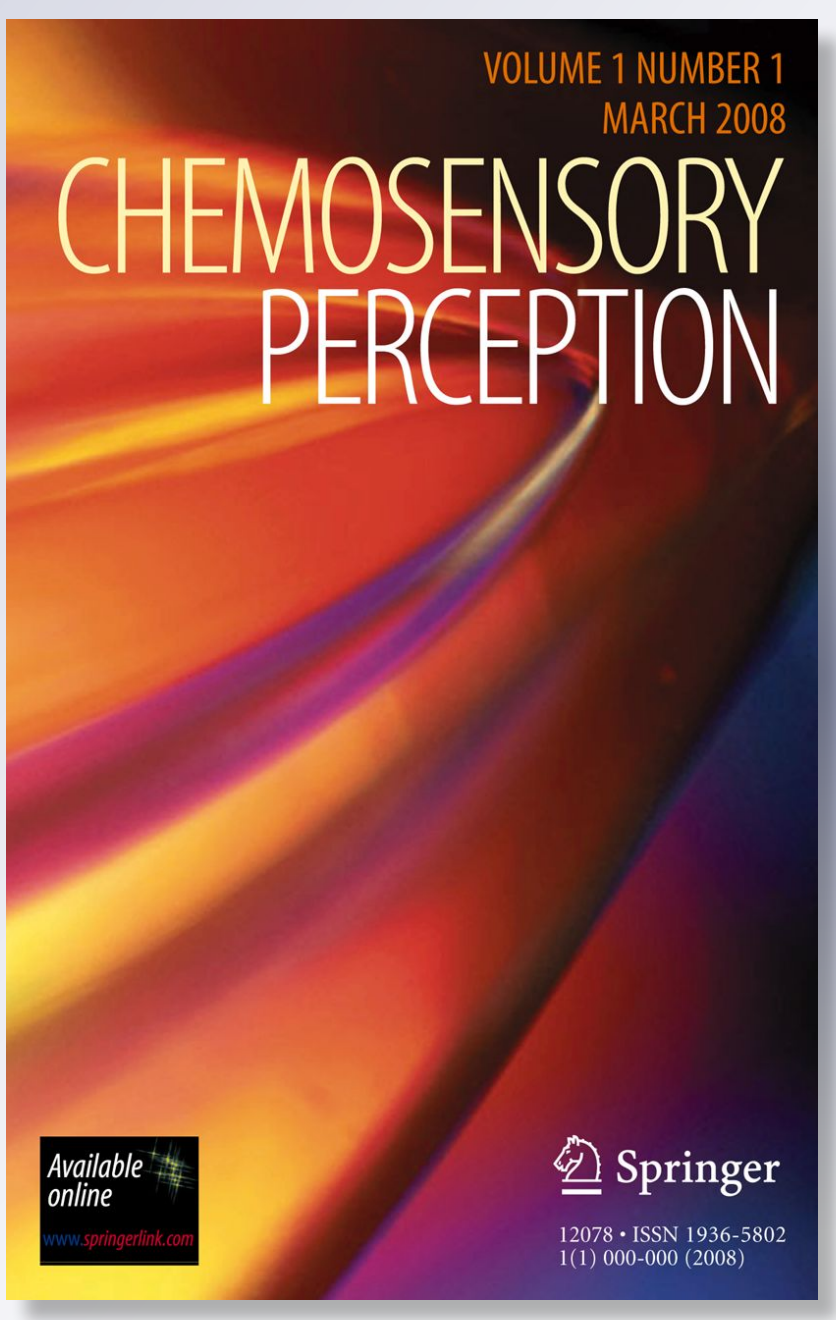

勿 Springer 
Your article is protected by copyright and all rights are held exclusively by Springer Science + Business Media, LLC. This e-offprint is for personal use only and shall not be selfarchived in electronic repositories. If you wish to self-archive your work, please use the accepted author's version for posting to your own website or your institution's repository. You may further deposit the accepted author's version on a funder's repository at a funder's request, provided it is not made publicly available until 12 months after publication. 


\title{
Emotional Responses to Pleasant and Unpleasant Oral Flavour Stimuli
}

\author{
Patrizia Muroni • Roberto Crnjar • \\ Iole Tomassini Barbarossa
}

Received: 15 December 2010 / Accepted: 18 July 2011 /Published online: 29 July 2011

(C) Springer Science+Business Media, LLC 2011

\begin{abstract}
The hedonic valence of taste perception plays a crucial role in the control of responses related to feeding behaviour. Taste and olfaction perception can induce autonomic responses, such as heart rate variability (HRV), which are involved in the evoked emotional reactions. Analysis of HRV can help distinguish sympathetic from parasympathetic regulation of the sinoatrial node. In this work, we analysed the HRV associated with oral flavour stimuli with opposite hedonic dimension and assessed their sympathovagal balance. ECGs were recorded continuously on 11 men and 12 women before and after stimulations. Experiments were performed in two sessions for comparison. ANOVA highlighted the decreases and increases of sinusal rhythm associated with pleasant and unpleasant flavour stimulations, respectively. Time and frequency domain analysis of HRV indicates that bradycardia induced by the pleasant stimulus can be attributed to an increase in the vagal tone, whilst tachycardia evoked by the unpleasant stimulus denotes a reduction of the vagal tone in women and an increase of the sympathetic tone in men. In conclusion, our data suggest that the HRV analysis may represent a valuable tool for autonomic nervous system response characterization associated to the hedonic dimen-
\end{abstract}

\footnotetext{
P. Muroni $\cdot$ R. Crnjar $\cdot$ I. Tomassini Barbarossa $(\bowtie)$

Department of Experimental Biology,

Section of General Physiology,

S.S. 554, Km 4.500,

09042 Monserrato, Cagliari, Italy

e-mail: tomassin@unica.it

P. Muroni

e-mail: pmuroni@unica.it

R. Crnjar

e-mail: crnjar@unica.it
}

sion of the complex flavour sensations induced by food and/or beverages.

Keywords Flavour perception · Heart rate variability Pleasantness · Unpleasantness · Sympathovagal tone

\section{Introduction}

The ability to distinguish nutrient-rich food sources from noxious substances is essential for an animal's survival (Scott 2005). Although olfaction and vision participate in food identification, taste and olfaction in concert act as a final checkpoint for food acceptance or rejection. These two senses can also evoke emotional responses (Norgren 1985; Van Toller 1998) due to their functional connections with brain structures involved in emotion, such as the hypothalamus and limbic system (Aggelton and Mishkin 1986; Anderson et al. 2003; Herz et al. 2004; Norgren 1985; Small et al. 2003). The hedonic dimension that a stimulus arouses in an individual plays a crucial role in the control of typical taste-mediated responses related to food ingestion or rejection (Smith and Vogt 1997). Pleasant taste stimuli evoke acceptance, whereas unpleasant ones elicit rejection, determining gustatory preference and aversion, respectively. Besides producing activation in the hypothalamus and limbic system, taste and olfactory perception can induce extremely fast autonomic nervous system (ANS) responses, such as heart rate variations, that can be considered diagnostic to discriminate different emotions. (AlaouiIsmaili et al. 1997a, b; Bensafi et al. 2002a, b, c; Heuberger et al. 2001; Horio 2000; Pössel et al. 2005; Robin et al. 1998, 1999; Rousmans et al. 2000). In addition, it is known that rating methods of these ANS responses can discriminate more different emotions, especially the negative ones, 
as compared with conscious methods, such as self-report (Alaoui-Ismaïli et al. 1997b).

Instantaneous heart rate (IHR), which represents the time course of sinusal rhythm, undergoes continuous fluctuations as a result of the sympathovagal balance changes (Appel et al. 1989; Bernardi et al. 1989). These fluctuations represent the physiological heart rate variability (HRV) in response to physiological perturbations which, by influencing the tone of the sympathetic and parasympathetic ANS, determine changes in the sinusal rhythm (Billman and Dujardin 1990; Conway et al. 1984; Eckberg 1980; Furlan et al. 1990; Grossman et al. 1990; McCraty et al. 1995; Molgaard et al. 1991). The analysis of HRV represents a measure of the cardiac autonomic regulation (Devlin et al. 2003; Gold et al. 2000; Holguin et al. 2003; Park et al. 2005) and helps distinguish sympathetic from parasympathetic regulation of the pacemaker activity of the sinoatrial node on the basis of latency differences of their respective action mechanisms (Ori et al. 1992; Task Force of the European Society of Cardiology and the North American Society of Pacing and Electrophysiology 1996). The HRV has been used to evaluate the effect of omega-3 polyunsaturated fatty acids on cardiovascular events (Romieu et al. 2005). Several studies reported that analysis of HRV represents a useful marker to characterize a number of psychological illnesses or to assess mental stress, thus providing a potential link between emotional states and HRV (Yeragani et al. 1991, 1993; Sloan et al. 1994). Moreover, the analysis of HRV has been used to show that such a negative emotion as anger produces increased sympathetic activity (McCraty et al. 1995; Sloan et al. 1994), whereas positive emotions can lead to alterations in sympathovagal balance that may be beneficial in the treatment of hypertension (McCraty et al. 1995). These findings lead to the hypothesis that analysis of HRV, by characterizing the ANS responses evoked by food perception, could be considered diagnostic to accurately discriminate the different emotions induced by food. Furthermore, HRV analysis turns out to be a faster objective (unconscious) rating method with respect to subjective methods (conscious) such as self-reports. In fact, self-report implies a cognitive analysis which cannot faithfully translate the emotional responses preceding cortical integration. Thus, if the use of verbal reports seems more suitable for studying the sensation cognitive component, such autonomic estimations as HRV would instead be more appropriate to evaluate the emotional aspects of food perception. The emotional aspects of food perception, which have both taste and olfaction components, can be better studied by analysing the effects of multimodal oral flavour stimuli, such as actual foods, than those evoked by separately unimodal taste or olfactory stimuli.

The aim of this work was to evaluate the emotional reactions associated with pleasant and unpleasant multi- modal oral flavour stimuli by the characterization of sinusal rhythm autonomic responses and HRV. We hypothesized to find heart rate variations selectively associated with the opposite hedonic dimension of flavour perception and to show that these variations result from specific shifting of the sympathetic-vagal balance. The neurovegetative characterization of ANS response related to emotional reactions could represent a reliable and objective tool for defining the hedonic dimension of food perception. Since the sympathetic and parasympathetic components of cardiac activity regulation are different in male and female (Evans et al. 2001; Dart et al. 2002), in this study, we analysed the sympathovagal balance variations in adult male and female subjects independently.

\section{Methods}

\section{Participants}

Twenty-three non-smoking volunteers (11 men and 12 women) were recruited at the local university according to standard procedures. All were Caucasian with ages from 21 to 28 years. The volunteers reported no variation of body weight greater than $5 \mathrm{~kg}$ over the previous 3 months. All were in good general health with no history of cardiovascular disease and free from deficits in taste or smell by selfreport. They were not following a prescribed diet or using medications that might interfere with taste or olfactory perception and were not currently taking prescription drugs capable of affecting cardiovascular function; none had food allergies. Subjects were verbally informed about the procedure and the aim of the study. Each subject reviewed and signed an informed consent form at the beginning of the protocol. The study was approved by the Ethical Committee of the University Hospital of Cagliari and has therefore been performed in accordance with the ethical standards laid down in the 1964 Declaration of Helsinki.

\section{Electrocardiographic Recordings}

Electrocardiograms (ECGs) were continuously recorded during experiments (before, during and after flavour stimulation) on each volunteer according to Einthoven's derivation I. The electric contact between skin and $\mathrm{Ag}-$ $\mathrm{AgCl}$ electrodes was made by means of a conductive ECG gel. ECG signals were derived, amplified and displayed on the screen of an oscilloscope (Tektronix $5111 \mathrm{~A}$; Tektronix Inc. Beaverton, OR), stored on a modified video recorder (Vetter; A.R. Vetter Co. Inc. Rebesburg, PA) and later analysed by a hardware and software integrated system (MacLab S System; ADInstruments Ltd., Castle Hill, Australia). 
Stimuli

The stimuli proposed for evoking flavour sensations with opposite hedonic tone were chosen on the basis of a verbal investigation performed on local university students in the preceding academic year. A nut chocolate cream $(\mathrm{CC}$; Nutella, Ferrero S.p.A.) and a lemon homogenate (LH) obtained from lemon pulp were adopted as stimuli capable of evoking a pleasant and an unpleasant sensation, respectively. A colourless, tasteless and odourless edible gelatine (C; cameo S.p.A.) was used as a control. All stimuli had a creamy consistency. Before starting the testing session, all stimuli were placed on a table in front of each volunteer in identical opaque beakers, in order to conceal their colour, and were presented at room temperature once as 10 -ml samples.

\section{Experimental Protocol}

The volunteers were requested to abstain from eating, drinking, using oral care products, chewing gums and doing physical exercise or overexerting for at least $4 \mathrm{~h}$ prior to testing. They had to be in the test room $15 \mathrm{~min}$ before the beginning of the session in order to adapt to the environmental conditions which were kept constant throughout the experimental session $\left(23-24{ }^{\circ} \mathrm{C}, 40-50 \%\right.$ relative humidity). They were seated in a comfortable chair. After positioning of electrodes, a further 20-min resting time was allowed before starting continuous ECG recording. Then, flavour stimulations were started. The first stimulus was presented 3 min after beginning of ECG recording. Stimuli were presented in a random order. For complete impregnation of the oral cavity, volunteers were instructed to keep each sample in the mouth for $5 \mathrm{~s}$ and then swallow it. Each stimulus was followed by oral rinsing with spring water. The interstimulus interval was set at $10 \mathrm{~min}$. After each stimulation, the subjects were requested to evaluate the stimulus on a five-point hedonic scale with a score varying from highly unpleasant $(-2)$ to highly pleasant (2).

Experiments were repeated on the same volunteers after a month's period (second test session) in order to confirm the results obtained in the first test session. In women, the tests were always carried out the sixth day of the menstrual cycle in order to avoid taste and olfaction sensitivity changes due to the oestrogen phase (Curtis et al. 2005; Di Lorenzo and Monroe 1990).

\section{Statistical Analysis}

Three-way analysis of variance (ANOVA) was used to compare the effects of flavour stimulations on scores of the hedonic ratings in women and men in the two test sessions.
The post hoc Tukey test was used for two-by-two comparisons.

In a continuous ECG recording, each cardiac cycle was detected by identifying the three-wave complex (QRS) that represents the electrical activity generated by ventricular depolarization preceding ventricular contraction. The duration of the interval between adjacent $\mathrm{R}$ waves (RR) of successive heartbeats were taken as a measure of IHR. A diagram called tachogram, which represents the interval RR between heartbeats as a function of the number of heartbeats, showed that changes of IHR following each flavour stimulation ended within a time frame of about $80 \mathrm{~s}$, corresponding to 100 heartbeats (data not shown). Therefore, we only took into consideration the IHR detected within the 100 cardiac cycles preceding and the 100 following each flavour stimulation. The effects of control stimulation on RR intervals were compared with the prestimulus values by one-way ANOVA. Three-way ANOVA was used to compare the effects of flavour stimulations on RR intervals in women and men in the two test sessions. The post hoc Tukey test was used for two-by-two comparisons. All differences were considered significant at a level of $p<0.05$. Statistical tests were conducted using Statistica for Windows (version 6.0, StatSoft Inc., Tulsa, OK, USA).

\section{Analysis of HRV}

The analysis of HRV can be made in the time and frequency domain starting from electrocardiographic recordings obtained over long or short time periods, provided that the measures of RR interval duration are reliable (Task Force of the European Society of Cardiology and the North American Society of Pacing and Electrophysiology 1996). We obtained the following time domain parameters: (a) the standard deviation of all normal RR intervals (SDNN) as a measure of both short- and long-term variability due to both sympathetic and parasympathetic activities and (b) the square root of the mean of the squares of successive RR interval differences (rMSSD), which is only influenced by the short-term fluctuations and computes the parasympathetic modulation (Stein 2002; Stein and Kleiger 1999). SDNN and rMSSD were calculated over the 100 cycles preceding and the 100 ones following each stimulation. Differences were compared by the "matched-paired" Student's $t$ test. Results obtained after the three stimulations in the first test session were compared with those of the second one by two-way ANOVA for repeated measures. The HRV analysis in the frequency domain was performed by estimating the fast Fourier transform and power spectral density over each RR interval tachogram using Chart 5HRV Module software (ADInstruments Ltd.). Each power spectrum was divided into two major frequency ranges: low 
frequency (LF, $0.04-0.15 \mathrm{~Hz}$ ), as a measure of total HRV due to both sympathetic and parasympathetic activities, and high frequency (HF, 0.15-0.4 Hz), exclusively due to the parasympathetic activity (Task Force of the European Society of Cardiology and the North American Society of Pacing and Electrophysiology 1996). The integral of power spectrum within each frequency range was calculated. Percentage changes in LF and HF power areas of the 100 cycles following pleasant and unpleasant stimulations with respect to the control were calculated and the differences compared by the "matched-paired" Student's $t$ test.

\section{Results}

Three-way ANOVA showed that the hedonic score varied with the type of applied stimulus $(F(2,126)=2,524.7, p<0.0001)$, but depended neither on the $\operatorname{sex}(F(2,126)=0.243, p=0.785)$ nor on the test session $(F(2,126)=0.1079, p=0.897)$. Post hoc comparison showed that the mean values \pm SEM of hedonic scores associated with each stimulation were significantly different from each other $(p<0.0001$, Fig. 1$)$. $\mathrm{CC}$ was rated as strongly pleasant, $\mathrm{LH}$ as strongly unpleasant and $\mathrm{C}$ neither pleasant nor unpleasant. Results of the two test sessions were equal. After taking the test, volunteers defined $\mathrm{CC}$ as having a sweet flavour, $\mathrm{LH}$ a sour flavour and $\mathrm{C}$ flavourless.

Multifactorial ANOVA revealed a two-way significant interaction of stimulus type $\times$ sex on RR interval following stimulation $(F(2,14388)=3.34, p=0.036)$, but showed no three-way interaction when including test session $(F(2,14388)=0.68, p=0.51$; Fig. 2$)$. Although the values of RR interval were higher in men as compared with women $(F(1,14388)=2441.9, p<0.001)$, in both sexes, the two-by-two comparison showed an increase $(p \leq 0.0021$ in women and $p \leq 0.0027$ in men) and a decrease ( $p \leq 0.00002$ in women and $p \leq 0.0022$ in men) of the RR interval mean associated with the pleasant and
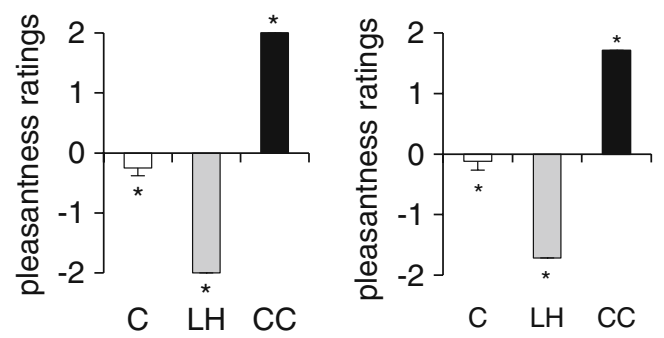

Fig. 1 Mean values \pm SEM of hedonic scores associated with each stimulation in women (left graph) and in men (right graph) in the first test session. All individuals rated -2 the unpleasantness of $\mathrm{LH}$ and +2 the pleasantness of $\mathrm{CC}$ in both test sessions. Results of the two test sessions were equal. *Significant difference $(p<0.0001$ in both sexes, post hoc Tukey test subsequent to three-way ANOVA). $C C$ nut chocolate cream, $L H$ lemon homogenate, $C$ control
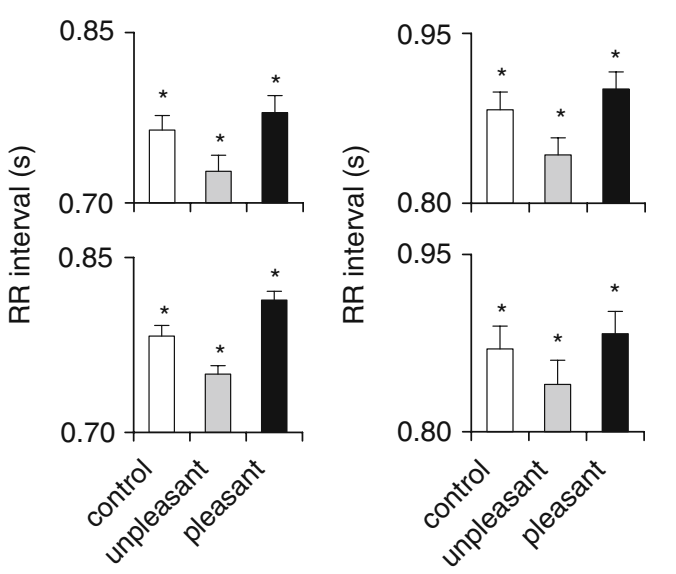

Fig. 2 Mean values \pm SEM of RR intervals of the cardiac cycles following each flavour stimulation measured in women (left graphs) and in men (right graphs) in the first test session (upper graphs) and in the second test session (lower graphs). *Significant difference ( $p \leq 0.0027$, post hoc Tukey test subsequent to three-way ANOVA)

unpleasant stimulations, respectively, against the control. Control stimulation did not produce significant changes of RR interval mean value $(p>0.05)$ with respect to the prestimulus value $(0.751 \pm 0.0037 \mathrm{~s}$ in the first test session and $0.749 \pm 0.0044 \mathrm{~s}$ in the second test session in women; $0.813 \pm 0.0031 \mathrm{~s}$ in the first test session and $0.819 \pm$ $0.00313 \mathrm{~s}$ in the second test session in men).

The results of time domain analysis of HRV performed over the cardiac cycles following each stimulation in both sexes in the first test session are shown in Fig. 3. In particular, SDNN (upper graphs) and rMSSD (lower graphs) after pleasant stimulation (black bars) increased

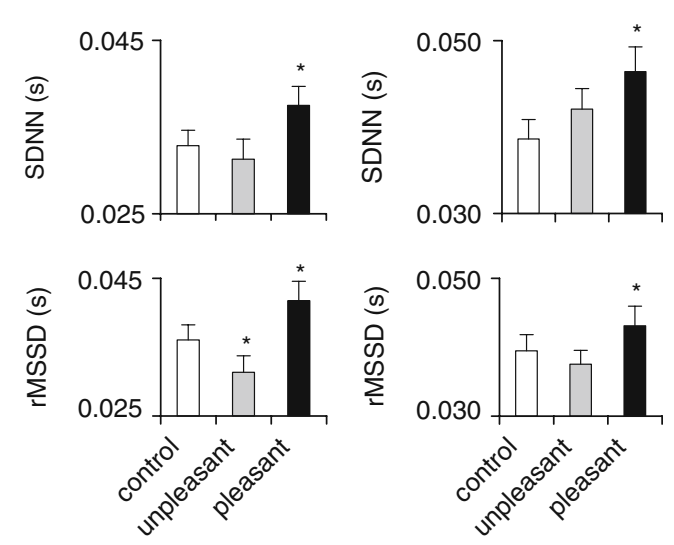

Fig. 3 Time domain analysis of HRV performed over the cardiac cycles following each stimulation in women (left graphs) and in men (right graphs) in the first test session. Mean values \pm SEM of SDNN (upper graphs) and mean values \pm SEM of rMSSD (lower graphs). No significant differences were found between SDNN and rMSSD calculated in the first and second test sessions $(p>0.05$, two-way ANOVA for repeated measures). *Significant difference from control stimulation values $(p \leq 0.0213$, matched-paired Student's $t$ test) 
with respect to control stimulation (white bars), both in women ( $p=0.0213$ and $p=0.0173$, respectively) and in men ( $p=0.0135$ and $p=0.0032$, respectively). After unpleasant stimulation, SDNN (grey bars, upper graphs) showed a tendency to decrease in women and increase in men, although not significant. Besides, rMSSD (grey bars, lower graphs) significantly decreased in women $(p=.0162)$ and tended to decrease in men. No significant differences were found between SDNN and rMSSD calculated in the first and second test sessions $(F(2,354)=0.3069, p=0.7358$, and $F(2,354)=0.2499, p=0.7789$, in women; $F(2,339)=0.1868$, $p=0.8296$, and $F(2,339)=0.5593, p=0.5781$, in men).

The frequency domain analysis of HRV of the cardiac cycles following pleasant and unpleasant stimulations is shown in Fig. 4. In the two sexes, both LF and HF power areas showed percentage increases following pleasant stimulation as compared with the control values $(p \leq 0.001)$, and in women, the increase of HF power area was higher than that of LF power area $(p=0.012)$. Differently, after unpleasant stimulation, HF power area increased only in women $(p=0.003)$ and LF power area increased only in men $(p=0.005)$, as compared with the control stimulation.

\section{Discussion}

In the present study, we determined the autonomic responses of sinusal rhythm and evaluated changes of the sympathetic-vagal balance to pleasant and unpleasant multimodal oral flavour stimuli. Our results suggest that the antagonist responses of sinusal rhythm are selectively associated with the opposite hedonic dimension of flavour perception. In fact, the nut chocolate cream and lemon homogenate, classified in the hedonic test as pleasant and unpleasant oral flavour stimuli, determine bradycardia and tachycardia, respectively, both in women and men. Instead, the neutral stimulus (control) resulted ineffective in induc-

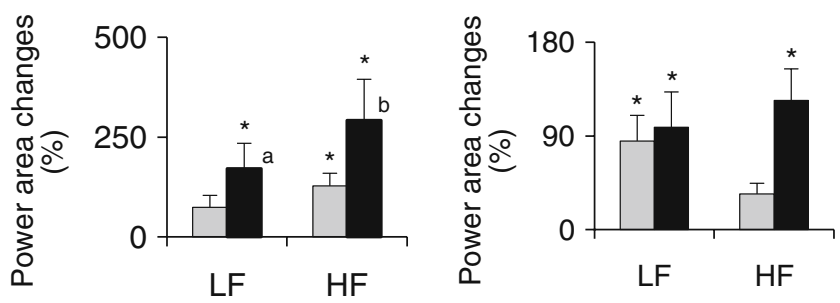

Fig. 4 Frequency domain analysis of HRV performed in women (left graph) and in men (right graph) in the first test session. Mean percentage changes $( \pm \mathrm{SEM})$ of LF and HF power areas of the cardiac cycles following pleasant (black bars) and unpleasant (grey bars) stimulation as compared with control values. *Significant difference ( $p \leq 0.005$, matched-paired Student's $t$ test). Different letters indicate significant difference ( $p=0.012$, matched-paired Student's $t$ test) ing changes of sinusal rhythm. Indeed, no changes of RR intervals were detected after control stimulation with respect to the pre-stimulus value. The fact that the control stimulus did not evoke variations from base activity supports the idea that the variations observed following pleasant or unpleasant stimulation are due to the stimuli themselves and not to the experimental procedure.

Furthermore, our results suggest that the antagonist responses of sinusal rhythm evoked by pleasant and unpleasant flavour stimulations are due to specific shifting of the sympathetic-vagal balance that, for the unpleasant stimulus, seems to be different in the two sexes. The time and the frequency domain analysis of HRV suggests that the bradycardia induced by the pleasant stimulus could be attributed to an increase in the vagal tone in both women and men. In fact, after the nut chocolate cream perception, we found an increase of SDNNs that represents an increase of both sympathetic and parasympathetic activities and of rMSSDs that indicate an increase of vagal tone. Besides, the pleasant stimulus produced the highest increase of power area in the HF range, which indicates a raise of parasympathetic activity. Conversely, tachycardia evoked by the unpleasant stimulus could be due to a reduction of the vagal tone in women and to an increase of the sympathetic activity in men. Indeed, after the lemon homogenate perception, we found a decrease of rMSSD and an increase of $\mathrm{HF}$ in women, whilst in men we observed an LF increase without HF increase and a trend to an increase of SDNN and to a decrease of rMSSD, which points to an increase of sympathetic activity.

The increase of vagal activity we found after pleasant perception might represent a preparatory mechanism for the responses associated with food ingestion, such as salivary secretion, swallowing, increased gastric motility and intestinal secretion, and a larger blood flow to the gastrointestinal system. Instead, the decrease of the parasympathetic tone induced in women by perception of the unpleasant stimulus might represent a restraint for responses related to food ingestion. In men, the increase of sympathetic activity evoked by unpleasant perception seems to flag a state of alert to avoid food intake. These results add evidence to the findings of several studies suggesting that men have a preponderance of sympathetic over vagal control of the cardiac function as compared with women who, on the contrary, have a preponderance of vagal over sympathetic responsiveness (Evans et al. 2001; Dart et al. 2002).

Our results also seem to suggest that the pleasant flavour stimulation, by evoking heart rate and HRV changes, might represent in human a natural rewarding mechanism for stress buffering, similar to what was observed in rats where the sucrose dessert paradigm reduces neuroendocrine, cardiovascular and behavioural responses to stress (UlrichLai et al. 2010). However, we found that the pleasant 
flavour stimulation induces bradycardia via an increase of the vagal tone, whilst Ulrich-Lai et al. (2010) showed that the sucrose dessert paradigm reduces restraint-induced tachycardia via a decrease of sympathetic drive. In addition, our data suggest that pleasant flavour stimulations, as previously shown for mental emotional states of appreciation (McCraty et al. 1995), may have a positive impact on cardiovascular function by causing a shifting of the sympathovagal balance towards a greater vagal activation.

In conclusion, our study indicates that the sinusal rhythm autonomic responses and HRV analysis can represent a simple, objective and reliable tool for the evaluation of emotional reactions associated with the hedonic dimension of flavour perception. Such neurovegetative characterization could then be used for the definition of hedonic dimension of complex flavour sensations induced by food and/or beverages and may find application for new product development and marketing in food industry.

Acknowledgements This work was supported by the Italian Ministry of University and Research. The authors thank the volunteers without whose contribution this study would not be possible. We also thank Dr. Giuseppe Cansella for his contribution to data analysis and Dr. Caterina Chillotti for running clinical trials.

\section{References}

Aggelton JP, Mishkin M (1986) The amygdala sensory gateway to the emotion. In: Plutchick R, Kellerman H (eds) Emotion: theory, research and experience. Biological foundations of emotion, vol 42. Academic, Orlando, pp 281-299

Alaoui-Ismaïli O, Vernet-Maury E, Dittmar A, Delhomme G, Chanel J (1997a) Odor hedonics: connection with emotional response estimated by autonomic parameters. Chem Senses 22:237-248

Alaoui-Ismaïli O, Robin H, Rada A, Dittmar A, Vernet-Maury E (1997b) Basic emotions evoked by odorants: comparison between autonomic responses and self-evaluation. Physiol Behav 62:713-720

Anderson AK, Christoff K, Stappen I, Panitz D, Ghahremani DG, Glover G, Gabrieli JD, Sobel N (2003) Dissociated neural representations of intensity and valence in human olfaction. Nat Neurosci 6:96-202

Appel ML, Berger RD, Saul JP, Smith JM, Cohen RJ (1989) Beat to beat variability in cardiovascular variables: noise or music? J Am Coll Cardiol 14(5):139-148

Bensafi M, Rouby C, Farget V, Bertrand B, Vigouroux M, Holley A (2002a) Autonomic nervous system responses to odours: the role of pleasantness and arousal. Chem Senses 27:703-709

Bensafi M, Rouby C, Farget V, Bertrand B, Vigouroux M, Holley A (2002b) Influence of affective and cognitive judgments on autonomic parameters during inhalation of pleasant and unpleasant odors in humans. Neurosci Lett 319(3):162-166

Bensafi M, Rouby C, Farget V, Bertrand B, Vigouroux M, Holley A (2002c) Psychophysiological correlates of affects in human olfaction. Neurophysiol Clin 32(5):326-332

Bernardi L, Keller F, Sanders M, Reddy PS, Griffith B, Meno F, Pinsky MR (1989) Respiratory sinus arrhythmia in the denervated human heart. J Appl Physiol 67(4):1447-1455
Billman G, Dujardin J-P (1990) Dynamic changes in cardiac vagal tone as measured by time-series analysis. Am J Physiol 258(3): H896-H902

Conway J, Boon N, Davies C, Jones JV, Sleight P (1984) Neural and humoral mechanisms involved in blood pressure variability. $\mathrm{J}$ Hypertens 2(2):203-208

Curtis KS, Stratford JM, Contreras RJ (2005) Estrogen increases the taste threshold for sucrose in rats. Physiol Behav 86:281-286

Dart AM, Du XJ, Kingwell BA (2002) Gender, sex hormones and autonomic nervous control of the cardiovascular system. Cardiovasc Res 53(3):678-687

Devlin RB, Ghio AJ, Kehrl H, Sanders G, Cascio W (2003) Elderly humans exposed to concentrated air pollution particles have decreased heart rate variability. Eur Respir J Suppl 40:76s-80s

Di Lorenzo P, Monroe S (1990) Taste responses in the parabrachial pons of ovariectomized rats. Brain Res Bull 25:741-748

Eckberg DW (1980) Parasympathetic cardiovascular control in human disease: a critical review of methods and results. Am Physiol 239:H581-H593

Evans JM, Ziegler MG, Patwardhan AR, Ott JB, Kim CS, Leonelli FM, Knapp CF (2001) Gender differences in autonomic cardiovascular regulation: spectral, hormonal and emodynamic indexes. J Appl Physiol 91(6):2611-2618

Furlan R, Guzzetti S, Crivellaro W, Dassi S, Tinelli M, Baselli G, Cerutti S, Lombardi F, Pagani M, Malliani A (1990) Continuous 24-hour assessment of the neural regulation of systemic arterial pressure and RR variabilities in ambulant subjects. Circulation 81 (2):537-547

Gold DR, Litonjua A, Schwartz J, Lovett E, Larson A, Nearing B, Allen G, Verrier M, Charry R, Verrier R (2000) Ambient pollution and heart rate variability. Circulation 101(11):1267-1273

Grossman P, van Beck J, Wientjes C (1990) A comparison of three quantification methods for estimation of respiratory sinus arrhythmia. Psychophysiology 27(6):702-714

Herz RS, Eliassen J, Beland S, Souza T (2004) Neuroimaging evidence for the emotional potency of odor-evoked memory. Neuropsychologia 42(3):371-378

Heuberger E, Hongratanaworakit T, Bohm C, Weber R, Buchbauer G (2001) Effects of chiral fragrances on human autonomic nervous system parameters and self-evaluation. Chem Senses 26:281-292

Holguin F, Tellez-Rojo MM, Hernandez M, Cortez M, Chow JC, Watson JG, Mannino D, Romieu I (2003) Air pollution and heart rate variability among the elderly in Mexico City. Epidemiology 14(5):521-527

Horio T (2000) Effects of various taste stimuli on heart rate in humans. Chem Senses 25:149-153

McCraty R, Atkinson M, Tiller W, Rein G, Watkins AD (1995) The effects of emotions on short-term power spectrum analysis of heart rate variability. Am J Cardiol 76(14):1089-1093

Molgaard H, Sørensen KE, Bjerregaard P (1991) Circadian variation and influence of risk factors on heart rate variability in healthy subjects. Am J Cardiol 68(8):777-784

Norgren R (1985) Taste and the autonomic nervous system. Chem Senses 10:143-161

Ori Z, Monir G, Weiss J, Sayhouni X, Singer DH (1992) Heart rate variability frequency domain analysis. Cardiol Clin 10(3):499537

Park SK, O’Neill MS, Vokonas PS, Sparrow D, Schwartz J (2005) Effects of air pollution on heart rate variability: the VA Normative Aging Study. Environ Health Perspect 113(3):304-309

Pössel P, Ahrens S, Hautzinger M (2005) Influence of cosmetics on emotional, autonomous, endocrinological, and immune reactions. Int J Cosmet Sci 27(6):343-349

Robin O, Alaoui-Ismaïli O, Dittmar A, Vernet-Maury E (1998) Emotional responses evoked by dental odors: an evaluation from autonomic parameters. J Dent Res 77(8):1638-1646 
Robin O, Alaoui-Ismaïli O, Dittmar A, Vernet-Maury E (1999) Basic emotions evoked by eugenol odor differ according to the dental experience: a neurovegetative analysis. Chem Senses 24(3):327335

Romieu I, Tellez-Rojo MM, Lazo M, Manzano-Patino A, Cortez-Lugo M, Julien P, Belanger MC, Hernandez-Avila M, Holguin F (2005) Omega-3 fatty acid prevents heart rate variability reductions associated with particulate matter. Am J Respir Crit Care Med 172:1534-1540

Rousmans S, Robin O, Dittmar A, Vernet-Mauri E (2000) Autonomic nervous system responses associated with primary tastes. Chem Senses 25(6):709-718

Scott K (2005) Taste recognition: food for thought. Neuron 48(3):455464

Sloan RP, Shapiro PA, Bigger JT, Bagiella E, Steinman RC, Gorman JM (1994) Cardiac autonomic control and hostility in healthy subjects. Am J Cardiol 74(3):298-300

Small DM, Gregory MD, Mak YE, Gitelman DR, Mesulam MM, Parrish TB (2003) Dissociation of neural representation of intensity and affective valuation in human gustation. Neuron 39 (4):701-711

Smith DV, Vogt MB (1997) The neural code and integrative processes of taste. In Beauchamp GK and Bartoshuk L (eds) Tasting and Smelling. Handbook of Peception and Cognition, Academic Press, San Diego, CA, pp 25-76
Stein PK (2002) Assessing heart rate variability from real-world Holter records. Card Electrophysiol Rev 6(3):239-244

Stein PK, Kleiger RE (1999) Insights from the study of heart role variability. Annu Rev Med 50:249-261

Task Force of the European Society of Cardiology and the North American Society of Pacing and Electrophysiology (1996) Heart rate variability. Standards of measurement, physiological interpretation and clinical use. Circulation 93(5):10431065

Ulrich-Lai YM, Christiansen AM, Ostrander MM, Jones AA, Jones KR, Choi DC, Krause EG, Evanson NK, Furay AR, Davis JF, Solomon MB, de Kloet AD, Tamashiro KL, Sakai RR, Seeley RJ, Woods SC, Herman JP (2010) Pleasurable behaviors reduce stress via brain reward pathways. PNAS 107(47):20529-20534

Van Toller S (1998) Emotion and the brain. In: Van Toller S, Dodd GH (eds) Perfumery: the psychology and biology of fragrance. Chapman \& Hall, London, pp 121-146

Yeragani VK, Pohl R, Balon R, Ramesh C, Glitz D, Jung I, Sherwood P (1991) Heart rate variability in patients with major depression. Psychiat Res 37:35-46

Yeragani VK, Pohl R, Berger R, Balon R, Ramesh C, Glitz D, Srinivasan K, Weinberg P (1993) Decreased HRV in panic disorder patients: a study of power-spectral analysis of heart rate. Psychiat Res 46:89-93 